NBER WORKING PAPER SERIES

\title{
SIZE INEQUALITY, COORDINATION EXTERNALITIES AND INTERNATIONAL TRADE AGREEMENTS
}

\author{
Nuno Limao \\ Kamal Saggi \\ Working Paper 17603 \\ http://www.nber.org/papers/w17603
NATIONAL BUREAU OF ECONOMIC RESEARCH
1050 Massachusetts Avenue
Cambridge, MA 02138
November 2011

Nuno Limao acknowledges the financial support of the UK Department of Development in the initial stage of this project. The views expressed herein are those of the authors and do not necessarily reflect the views of the National Bureau of Economic Research.

NBER working papers are circulated for discussion and comment purposes. They have not been peerreviewed or been subject to the review by the NBER Board of Directors that accompanies official NBER publications.

(C) 2011 by Nuno Limao and Kamal Saggi. All rights reserved. Short sections of text, not to exceed two paragraphs, may be quoted without explicit permission provided that full credit, including $\odot$ notice, is given to the source. 
Size Inequality, Coordination Externalities and International Trade Agreements

Nuno Limao and Kamal Saggi

NBER Working Paper No. 17603

November 2011

JEL No. F13,F42,K33,O1,O24

\begin{abstract}
$\underline{\text { ABSTRACT }}$
Developing countries now account for a significant fraction of both world trade and two thirds of the membership of the World Trade Organization (WTO). However, many are still individually small and thus have a limited ability to bilaterally extract and enforce trade concessions from larger developed economies even though as a group they would be able to do so. We show that this coordination externality generates asymmetric outcomes under agreements that rely on bilateral threats of trade retaliation. such as the WTO. but not under agreements extended to include certain financial instruments. In particular, we find that an extended agreement generates improvements in global efficiency and equity if it Includes the exchange of bonds prior to trading but not if it relies solely on ex-post fines. Moreover, a combination of bonds and fines generates similar improvements even if small countries are subject to financial constraints that prevent them from posting bonds.
\end{abstract}

Nuno Limao

Department of Economics

University of Maryland

3105 Tydings Hall

College Park, MD 20742

and NBER

limao@econ.umd.edu

Kamal Saggi

Vanderbilt University

Department of Economics

VU Station B\# 351828

2301 Vanderbilt Place

Nashville, TN 37235-1828

k.saggi@vanderbilt.edu 


\section{Introduction}

International trade relations between developed and developing countries have often been adversarial. As early as 1947, some developing countries were denouncing U.S. proposals for the predecessor of the World Trade Organization (WTO) as "serving the interests of developed countries and undermining the development prospects of poor countries" (Srinivasan, 1999, p. 1050). More recently, the Uruguay Round was seen by most developing countries as having produced a multilateral bargain that is biased heavily in favor of developed countries. Partly to rectify the perceived imbalance of the Uruguay Round outcome, the Doha Development Round was launched in 2001 with the idea that it would put the interests of developing countries at the forefront. ${ }^{1}$

Developing countries now account for two thirds of the 153 WTO members (up from 11 in the GATT) and over a third of world trade and have increasingly begun to demand a more active voice in multilateral negotiations. However, they still face considerable challenges in translating such demands into tangible outcomes: despite being over a decade old, the Doha Round shows no signs of concluding anytime soon. In this paper we analyze a key problem that developing countries face in trying to achieve a more favorable outcome in international trade negotiations - i.e. the presence of a coordination externality among themselves. Even though developing countries are now large on aggregate, most are still individually small and thus have a limited ability to bilaterally extract and enforce trade concessions from larger developed economies. We show that under standard agreements that rely on bilateral threats of trade retaliation - such as the WTO - this coordination externality generates asymmetric outcomes that are less favorable to developing countries (as well as globally) than those obtained under an agreement extended to include certain types of financial instruments.

The traditionally dominant role of large countries in the world trading system is partly due to the bilateral and reciprocal nature of negotiations in international trade agreements such as the GATT/WTO. The key idea is simple: if the EU wants lower US tariffs on its exports then it must reciprocate with lower tariffs on goods it imports from the US. Note, however, that this reciprocal exchange relies on the presence of relatively symmetric market power on both

\footnotetext{
${ }^{1}$ The Doha ministerial declaration of November 2001 states: "We recognize the need for all our peoples to benefit from the increased opportunities and welfare gains that the multilateral trading system generates. The majority of WTO members are developing countries. We seek to place their needs and interests at the heart of the Work Programme adopted in this Declaration."
} 
sides: while a tariff reduction by a country with a sufficiently high import share and market power increases the price received by foreign exporters, no significant bilateral concessions occur when the reduction is undertaken by a small country. ${ }^{2}$ Market power is also key in enforcing cooperation since the threat to abandon the agreement and increase tariffs on the part of a country that lacks such power is not credible and therefore fails to act as a useful deterrent. Thus, bilateral asymmetries in market power undermine international cooperation and may explain why some exports from (smaller) developing countries (e.g. in agriculture, textiles, some manufactures) have historically faced relatively higher tariffs in (larger) developed countries. By undermining cooperation, this asymmetry can also lead to higher tariffs by developing countries but as long as they remain small as a group, the large countries do not lose much from this, which may explain why the latter have not pushed developing countries to liberalize further until recently. ${ }^{3}$

Most formal analyses of the GATT/WTO focus on two large countries. ${ }^{4}$ The focus on this canonical case has yielded important insights and was a reasonable approximation of actual negotiations at the GATT/WTO since up until the Uruguay Round these negotiations were led primarily by the US and Europe (c.f. Schott, 2009). However, the global economic landscape has changed significantly with the emergence of BRICs - Brazil, Russia (which may soon join the WTO), India and China. From 2000 to 2009 alone the world import share of the largest traders, the US and EU, fell from $43 \%$ to $34 \%$ (54\% to $42 \%$ if we also include Japan and Canada) and their bilateral trade accounts for less than $20 \%$ of their total trade. ${ }^{5}$ The relative decline of the US and EU in world trade suggests that it is important to analyze international trade agreements between multiple countries of asymmetric size, something that we focus on

\footnotetext{
${ }^{2}$ For evidence of the positive relationship between market power and either import shares or GDP see Broda, Limao and Weinstein (2008).

${ }^{3}$ In fact, if the asymmetry is sufficiently large, the large country would be strictly better off by not cooperating (cf. Johnson, 1953-54). An additional explanation for relatively higher tariffs by the large developed countries on exports of small developing countries is that historically the latter have tended to not take an active role in multilateral trade negotiations. One reason for such non-participation and higher tariffs by large countries arises when, as in our setup, a large country imports the same good from many small countries. Ludema and Maya (2009) show how the WTO MFN rule requiring the importer to set the same tariff on all exporters lowers the incentive for the latter to participate in reciprocal negotiations in an attempt to minimize reductions in their own tariffs. Since this incentive is well understood theoretically we abstract from it (by assuming all exporters either participate or not) and focus instead on the coordination externality.

${ }^{4}$ See for example Mayer (1981), Grossman and Helpman (1995) and Bagwell and Staiger (1999). Both the latter and Saggi (2006) also consider a third large country to study tariff discrimination.

${ }^{5}$ Authors calculations based on data from the WTO's "International trade statistics 2010". We treat the EU as a country since it has a common tariff and negotiates as a block thus world imports exclude flows within EU-27.
} 
this paper.

While some of the recent decline of the US and EU in world trade is mirrored in the rise of BRICs - particularly China - there is also a longer trend driven by other developing countries' trade liberalization and growth. ${ }^{6}$ This is important in motivating the coordination externality underlying our model since this externality is most relevant if several countries jointly account for a non-negligible amount of exports of a larger country. For example, in 2009 Asia accounted for $14 \%$ of US exports if we exclude Japan, Australia and China, but the remaining 10 top Asian importers of US goods had a median share of only $1.3 \%$ and still accounted for $13 \%$ of US exports (the largest is Korea with less than 3\%). Another case in point is South and Central America: while the region jointly accounts for $10 \%$ of US exports all but one country accounts for less than $1 \%$ (the only exception is Brazil, whose share is $2.5 \%$ ). More broadly, if in 2009 the US were to negotiate only with the top 5 destinations for its products it would cover only $64 \%$ of its exports, with the analogous figure for the EU being even smaller (44\%). ${ }^{7}$

Our model highlights the role of bilateral size asymmetry in international trade agreements by focusing on two "regions" of similar size with one containing a single large country and the other multiple countries each of whom individually has less market power in trade. The large country exports a single good, $x$, to all small countries and imports a different good in return. The bilateral size asymmetry generates lower tariffs and welfare for the smaller countries in the absence of an agreement because their tariff choices are subject to a coordination externality, i.e. when setting its tariff on good $x$ each small country ignores any positive terms-of-trade effect that its tariff has on all other importers of the same good. We then show that this imbalance remains even if countries cooperate through a standard trade agreement that relies on the threat of tariff retaliation because cooperation is ultimately sustained by the threat of non-cooperative tariffs, which are subject to the coordination externality. ${ }^{8}$ The small countries

\footnotetext{
${ }^{6}$ As the Director General of the WTO notes "Between 1973 and 1997 the developing countries' share of manufactured imports in developed markets tripled - from 7.5 per cent to 23 per cent. What these figures reflect is the developing world's truly remarkable integration into the global economy over the past three decades." Source: Ruggiero (1999) accessed at <http://www.wto.org/english/news_e/pres99_e/pr122_e.htm>. Besedes and Prusa (2010) examine the sources of export growth for 46 countries between 1975-2003.

${ }^{7}$ Moreover, the recent increases in this dispersion measure suggests an increasingly important role for the coordination externality among importers of US goods. For example, the top 5 US destinations in 2000 accounted for $70 \%$ of its exports but those in 2009 only accounted for $64 \%$. At the industry level we see a similar trend with over $2 / 3$ of HS 2 industries showing declines averaging 7 p.p. in the share of top 5 destinations (the average for those with an increase was about 4 p.p.).

${ }^{8}$ We should note that tariff retaliation at the WTO is permitted as a last resort after negotiations between the affected parties have failed and any panel ruling calling for compliance has gone unheeded by the defendant.
} 
would gain from jointly threatening higher tariffs to punish any deviation by the large country but this threat is not credible: in the event the agreement breaks down, each small country has an individual incentive to free ride on the others if they were to try punishing the large country via a jointly optimal Nash tariff.

Next, we examine how standard agreements - i.e. those based on tariff retaliation alone - can be reformed to counter the coordination externality and generate more efficient and equitable (i.e. symmetric) outcomes. More specifically, we extend the standard trade agreement to include financial instruments, i.e. some form of monetary payment incurred by countries who deviate from the agreement. Such instruments have been proposed in the WTO, particularly by developing countries arguing that their limited market power prevents them from using tariffs to obtain proper compensation in case of a violation. ${ }^{9}$ It is straightforward to see that if a violation does occur and compensation to the injured party can be enforced then it is more efficient to use a monetary transfer than a distortionary instrument such as a tariff. What existing proposals typically neglect however, and what we focus on, is the more difficult question of how financial compensation can be enforced and whether such instruments can deter deviations and generate more cooperation ex-ante. ${ }^{10}$

We show that agreements extended to include specific financial instruments can enhance cooperation and generate outcomes that are more symmetric relative to a standard trade agreement. In particular, we show those improvements occur when countries exchange bonds prior to trading and agree to forfeit them in case of a violation. This financial instrument targets the coordination externality by removing the need for small countries to threaten non-credible high tariffs; by requiring a high enough bond to be posted ex-ante we remove the incentive of the large country to deviate (so as not to forfeit its bond). ${ }^{11}$ The appropriate choice of financial instrument is therefore crucial and in fact we show that the obvious alternative, i.e. a monetary

\footnotetext{
${ }^{9}$ Such proposals have gained substantial attention in recent years during the Doha Round (cf. TN/DS/W/9, 2002) but have not yet been adopted. Earlier proposals as early as the 1960's were put forward by developing countries such as Brazil and Uruguay. For a recent, in-depth discussion of the legal and economic arguments in favor of financial compensation as a means for settling trade disputes see Bronckers and Van Den Broek (2005).

${ }^{10}$ The financial transfers do not have to come directly from the country that violates the agreement. For example, Mexico has proposed that countries should be allowed to sell their right to retaliate to others that possess more market power to retaliate. This proposal has been analyzed by Bagwell et. al. (2007) in an auction framework that assumes the violation has already occurred and a country has "earned" the right to retaliate against another (offending) country. They show that in some cases it is the offending country that wins that auction so the transfer is direct but that is not always the case.

${ }^{11}$ We further show that this benefit of bonds relative to the standard agreement is eliminated when the number of countries goes to 2 (symmetric) ones, which is the special case that Limão and Saggi (2008) study.
} 
fine, does not by itself improve on the standard agreement. The reason is precisely that the payment of a fine must be made by the violating country and must still be enforced by small countries through the threat of tariff retaliation that is subject to the coordination externality.

There are potentially important obstacles in reforming standard agreements to include financial instruments. The main obstacle we consider in our analysis is the limited ability to post bonds with trading partners. We show that the results are robust to some bond constraints even if they are severe for small countries provided the extended agreement includes both bonds (posted by the large country) and fines. However, if the bond constraint is also severe for the large country then this extended agreement results in the same outcome as the standard trade agreement.

Our basic approach is common in the literature on trade agreements: we model such agreements as an equilibrium outcome of repeated interaction between governments. However, most of this literature ignores the role of financial instruments. An exception is Bagwell and Staiger (2005) who show that if governments face private anticipated shocks then cash transfers can help enforce more cooperative tariffs. However, Limão and Saggi (2008) show that their result will not hold if we instead consider fines enacted in the case of a deviation. The fact that different types of financial instruments lead to different levels of tariff cooperation highlights the importance of carefully modelling each of their roles in international trade agreements. Unlike these two papers, we examine countries that are asymmetric in their market power. Park (2000) also examines cooperation between asymmetric countries but focuses on a case where there is a single small country with no market power and one large country; he shows that cash transfers from the former to the latter can help enforce lower tariffs. This purchase of market access by a single infinitesimally small country is fundamentally different from the coordination externality among many small countries that we analyze and argue is empirically relevant. Thus the results we find are naturally different, e.g. we find that cooperation in tariffs can be achieved without requiring the small countries to purchase market access from the large country.

The paper is structured as follows. In section 2 we set up the model and describe the policy externalities. In section 3 we derive the policy and welfare impacts of standard agreements, contrast them with the extended agreements and analyze the implementation issues that may arise. We conclude in section 4. 


\section{$2 \quad$ Setup and Trade Policy Externalities}

\subsection{Setup}

The economic structure within each country is a standard one in the analysis of trade agreements (c.f. Limão and Saggi, 2008). However, instead of focusing on two symmetric countries, we allow for multiple asymmetric countries. To clearly highlight the role of size asymmetries we focus on a single large country trading with $K>1$ smaller countries, where the latter are identical among themselves.

Given the similar preferences and technologies across all countries, we describe the setup in detail for the large country (using variables without asterisks), and then point out any modification for the small ones. Each country can produce two homogeneous goods, $i=x, y$ and a numeraire, $n$. Individual utility over the consumption levels, $c$, of these goods is given by $u \equiv c_{n}+\sum_{i} u_{i}\left(c_{i}\right)$. Since utility is quasi-linear, the demand function for good $i$ depends only on its own price and is similar for all individuals so we denote aggregate demand by $D_{i}\left(p_{i}\right)$.

Each unit of the numeraire, $c_{n}$, is produced with a constant returns to scale technology using only labor. Each non-numeraire good is also produced with a constant returns technology but it uses both labor and a specific factor. We denote the supply function for non-numeraire goods by $S_{i}\left(p_{i}\right)$, omitting its dependence on the specific factor endowment since both labor and specific capital endowments are assumed constant and inelastically supplied.

We assume that the large country is a mirror image of the set of small countries so it imports one of the non-numeraire goods, which we label $y$, and exports the other, $x$. Under trade, the domestic import price in the large country is then $p_{y}=p_{y}^{w}+\tau$ where $p^{w}$ is the "world" price and $\tau$ is a specific import tariff on $y$. The large country's imports of $y$ are then $M_{y} \equiv D_{y}\left(p_{y}\right)-S_{y}\left(p_{y}\right)$ and its world price is determined by the market clearing condition

$$
M_{y}\left(p_{y}^{w}+\tau\right)+\sum M_{y}^{* k}\left(p_{y}^{w}\right)=0
$$

where $M_{y}^{* k}$ denote exports of good $y$ by each of the $k$ small countries. A similar condition applies to good $x$.

We assume that no export policies are available so trade policy is described by the level of the import tariff in each country. Reductions in the large country's import demand affect the world price of $y$ and it is simple to verify that in this setup an increase in the large country's tariff lowers the world price, $p_{y}^{w}(\tau)$, and raises the domestic one. Similarly, if the $K$ small countries 
jointly increased their tariffs on $x$ they would reduce its world price; i.e. small countries as a whole also have market power in trade.

The government chooses trade policies that maximize the political objective function below, which reflects social welfare and allows for extra weight $\left(\lambda_{i} \geq 1\right)$ on specific factor owners: ${ }^{12}$

$$
W\left(\tau, \tau^{*}\right) \equiv \sum_{i}\left[\int_{p_{i}}^{\infty} D_{i}\left(p_{i}\right) d p_{i}+\lambda_{i} \int_{0}^{p_{i}} S_{i}\left(p_{i}\right) d p_{i}+\tau_{i} M_{i}\left(p_{i}\right)\right]+L
$$

where we recall that the tariff $\tau$ affects $W$ both directly through tariff revenue, the term $\tau_{y} M_{y}$, and through its effect on home prices; whereas the effect of small countries' import tariffs, $\tau^{*}$, is indirect and occurs only through the world price, $p_{x}^{w}\left(\boldsymbol{\tau}^{*}\right)$. In equation $(2)$, the first term in parenthesis is consumer surplus; the second term can be interpreted as producer surplus or the quasi-rents accruing to the fixed factor owners; and the last term, $L$, is simply the total wage income of the large country when the wage is unity. ${ }^{13}$

Each of the individual small countries has an objective function, which is denoted by $W^{* k}$. It has the same functional form as (2) so we do not rewrite it but simply note that it is evaluated using the prices and endowments in each $k$. To simplify the exposition and focus on the size asymmetry we now describe some restrictions. Each of these $K$ small countries owns a constant fraction $(1 / K)$ of its region's population $\left(L^{*}\right)$ so $L^{* k}=L^{*} / K$ and of its specific inputs. Moreover, given similar preferences, technologies and political parameters in the region $\left(\lambda_{i}^{* k}=\lambda_{i}^{*}\right)$, the only potential difference that can arise across $W^{* k}$ is if some $k$ faces different prices because it sets or faces different tariffs than the others. It will often be useful to focus on equilibria where all small countries set a similar tariff, $\tau^{*}=\tau^{* k}$ for all $k$ and face the same tariff exporting to Large, $\tau$, which can be different from $\tau^{*}$. In this case prices and quantities are identical for all $k$ so, given constant returns, the aggregate variables for the region are $Z_{i}^{*} \equiv \Sigma_{k} Z_{i}^{* k}\left(p_{i}^{* k}\right)=K Z_{i}^{* k}\left(p_{i}^{*}\right)$ (where $\left.Z^{*}=D^{*}, S^{*}, M^{*}\right)$. Moreover, the aggregate political welfare in the region when $\tau_{i}^{* k}=\tau_{i}^{*}$ and $\lambda_{i}^{* k}=\lambda_{i}^{*}$ is $W^{*} \equiv \Sigma_{k} W^{* k}=K W^{* k}$.

We also assume that the two regions as a whole have similar population $\left(L=L^{*}\right)$ and similar supply of fixed factors in their respective import and export sector. This symmetry assumption implies that the "aggregate" market power of small countries is no different from that of the large country. This simplifies our exposition and is not crucial for our results; the

\footnotetext{
${ }^{12}$ This can be obtained as the reduced form of a political economy model such as Grossman and Helpman (1994).

${ }^{13}$ We assume there is sufficient labor to ensure a positive supply of the numeraire so that the wage rate in the economy is fixed by the marginal productivity of labor in the numeraire, which is normalized to unity.
} 
same is true of our assumption of similar political weights in each region $\left(\lambda_{y}=\lambda_{x}^{*}=\lambda\right)$ and their absence in the respective export sectors $\left(\lambda_{x}=\lambda_{y}^{*}=1\right)$.

\subsection{Trade Policy Externalities among Asymmetric Countries}

The large country's Nash tariff is obtained by maximizing (2) while taking the small countries' tariffs as given. Since we do not model export policies we drop the good subscript, $i$, and any subscripts below denote partial derivatives. Large's Nash tariff on $y$ solves

$$
\tau^{N} \equiv \arg _{\tau} \max W\left(\tau, \boldsymbol{\tau}^{*}\right)
$$

Recalling that the equilibrium prices are a function of tariffs, the first order condition for $\tau$ is

$$
-D p_{\tau}+\lambda S p_{\tau}+M+\tau M_{p} p_{\tau}=0
$$

Using $M=D-S, p_{\tau}=p_{\tau}^{w}+1$ and the elasticity expressions defined below we obtain a Nash tariff in ad-valorem terms, $\tau^{N} / p^{w}(\tau)$, implicitly defined by:

$$
\frac{\tau^{N}}{p^{w}(\tau)}=\frac{1}{\varepsilon(\tau)}+(\lambda-1) \frac{S(\tau) / M(\tau)}{\xi(\tau)}
$$

We show the potential dependence of the endogenous variables on the tariff. We do so for clarity in the formula but will omit them below for notational simplicity. The first term, $1 / \varepsilon \equiv M^{*} /\left(p^{w} M_{p}^{*}\right)$, is the inverse of the elasticity of the aggregate export supply curve of small countries (since $\tau$ applies to all small countries) and it reflects the large country's terms-oftrade motive for the use of tariffs. The second term reflects a political economy motive that is increasing in the extra weight placed on specific factor owners $(\lambda)$ and decreasing in the large country's import demand elasticity $\xi$ where $\xi \equiv-\left(\partial M / \partial p^{w}\right)\left(p^{w} / M\right)=-M_{p} p^{w} / M$.

If the small countries can't successfully coordinate their tariff choices, then the Nash tariff of an individual small country in its import sector, $x$, is

$$
\frac{\tau^{* N k}}{p^{w}}=\frac{1}{\varepsilon^{* k}}+(\lambda-1) \frac{S^{* k} / M^{* k}}{\xi^{* k}}
$$

where all the variables are defined similarly to $\tau^{N}$ in (5) but from the perspective of country $k$, as detailed in the appendix.

A country's import tariffs lowers the price received by exporters of that good, this is the standard negative terms-of-trade externality, which we will confirm below is a central reason for 
a trade agreement. However, the outcome of that agreement will depend on another externality that is present when there are several countries importing the same good, what we will refer to as a coordination externality. To understand it suppose that small countries could coordinate their tariffs choices in order to maximize their region's aggregate objective, $\Sigma_{k} W^{* k}$, then their Nash tariff, denoted by $\tau^{* N}$, would be given by (6) evaluated at the aggregate regional quantities $\left(S^{*} / M^{*}\right)$ and elasticities, $\varepsilon^{*}$ and $\xi^{*}$.We now argue that small countries set a higher tariff when acting jointly than individually because their market power is higher under coordination. We show this by contradiction. Suppose $\tau^{* N k}$ and $\tau^{* N}$ are identical and then evaluate the termsof-trade and political economy components of welfare. Note that given the symmetry across small countries we have a similar $\tau^{* N k}$ across all of them and thus a similar price, therefore $\left(S^{* k} / M^{* k}\right) / \xi^{* k}=\left(S^{*} / M^{*}\right) / \xi^{*}$, so if $\tau^{* N k}=\tau^{* N}$ and thus prices were identical then the political economy component would be identical. However, if we evaluate the export supply elasticities at similar prices then we can show that $1 / \varepsilon^{* k}<1 / \varepsilon^{*}$ if $K>1$, (see the appendix for an exact expression). The intuition for this is simple, when small countries set their tariffs independently, each small country does not take into account the positive terms-of-trade benefits that accrue to other small countries. As might be expected, this coordination externality is increasing in the number of countries.

The empirical relevance of the expressions above in tariff policy setting requires at least three pieces of evidence. First, countries should have at least some market power in imports. Second, prior to trade agreements countries should set higher tariffs on products with higher market power. Third, larger countries (in terms of GDP or import quantities) should have more market power than smaller countries. Evidence for each of these is provided by Broda, Limão and Weinsten (2008). ${ }^{14}$ Evidence for the third point is particularly relevant for this paper since as we divide a region of given size into a larger number of small countries (i.e. as $K$ increases) the GDP and imports of each shrinks, which is what drives down their relevant measure of market power, $1 / \varepsilon^{* k}$.

As we noted before, to highlight the size differences it is useful to keep other factors constant. If we assume symmetry across regions in their respective import and export sectors then we can easily see two other implications. First, $\tau^{N}=\tau^{* N}$ and so the lack of coordination among small countries would in this case imply that they have lower tariffs than the large one. ${ }^{15}$ Second, if

\footnotetext{
${ }^{14}$ They also find evidence of a positive impact of the political economy component, captured by $(S / M) / \xi$.

${ }^{15}$ Note that $\tau^{N}$ applies to good $y$ and is independent of the tariffs that small countries set on $x$ because the utility function is quasilinear and separable and on the supply side the only mobile factor is labor, which has a
} 
there were no enforcement problems, then countries could choose tariffs to maximize their joint objective $W+K W^{* k}$. With symmetric regions this is equivalent to maximizing the objective of either region after imposing $\tau=\tau^{*}$. Thus we obtain

$$
\tau^{G} \equiv \arg _{\tau^{C}} \max W\left(\tau^{C}, \tau^{*}=\tau^{C}\right)
$$

so the globally optimal ad-valorem tariff $\tau^{G} / p^{w}\left(\tau^{G}\right)$ (derived in the appendix) is

$$
\frac{\tau^{G}}{p^{w}(\tau)}=(\lambda-1) \frac{S(\tau) / M(\tau)}{\xi(\tau)}
$$

It is simple to see that $\tau^{G} / p^{w}<\tau^{N} / p^{w}$. The difference between the Nash and globally cooperative policies confirms that market power in trade leads to international externalities motivating the need for a trade agreement (Bagwell and Staiger, 1999). Note also that even in the presence of an international agreement, countries may choose to have positive tariffs due to internal political economy distortions (i.e. when $\lambda>1$ ). ${ }^{16}$

Since the globally optimal tariff $\tau^{G}$ is below the level that is optimal for each individual country, each country has an incentive to deviate from it and would do so if it faced no punishment. Before addressing how the threat of tariff retaliation can be used to sustain international cooperation, we make an important observation. Note from (6) that if the number of small countries is sufficiently high and governments face no political pressures (i.e. $\lambda=1$ ), the Nash tariff of each small country in the absence of coordination among them, $\tau^{* N k}$, approaches zero. Under such circumstances, a small country cannot individually offer any tariff reduction to the large country nor can it credibly threaten the large country with any tariff retaliation in case the latter reneges on a cooperative trade agreement. Thus, as $K$ increases so does the coordination externality and this lowers the incentive of the large country to enter into any agreement that relies only on uncoordinated tariff retaliation to enforce cooperation. Naturally if $K$ is so high that the value of $\tau^{* N \kappa}$ is close to the global optimum $\tau^{G}$ then the large country would always prefer not to cooperate at all. On the other hand, an individual small country has a much stronger incentive to cooperate since it has limited ability to manipulate its terms of trade. In what follows, we assume that $K \in(1, \bar{K}]$, i.e. there is more than one "small" country wage pinned down by the numeraire sector productivity .

${ }^{16}$ Broda et al (2008) provide evidence that countries set higher protection in goods where they have higher market power if they are either non-WTO members or the policy is not subject to strong WTO discipline. Bagwell and Staiger (2011) find that WTO accession leads to greater tariff reductions in products with higher initial import volumes and market power. 
(thus the asymmetry) but not so many of them as to make their cooperation unattractive to the large country. ${ }^{17}$

\section{Trade Agreements among Asymmetric Countries}

\subsection{Standard Agreements: Asymmetric Outcomes under Tariff Retaliation}

We now examine the role of agreements in enforcing tariff cooperation between asymmetric countries. We show that if standard agreements, which rely solely on tariff threats, can't sustain the globally optimal tariff for all countries then the outcome is an asymmetric one with a higher tariff set by the large country than the small ones (Proposition 1). The asymmetry is driven by the coordination externality previously highlighted. In the next section, we show that if we go beyond the enforcement instruments in standard agreements and include financial ones then we can both improve cooperation and make the outcome more equitable by sustaining the symmetric global tariff (Propositions 2 and 3).

Consider an infinitely repeated game where the stage game delivers the Nash tariffs previously derived, i.e. $\tau^{N}$ and $\tau^{* N k}$. Assume that countries observe each other's actions at the end of each period. The strategy for each country is to cooperate until any country deviates by raising its tariff. Any such deviation is followed by a punishment of $n$ periods during which the country that originally deviated faces Nash tariffs on its exports and demonstrates its willingness to restart cooperation by setting a cooperative tariff level. If this occurs then cooperative tariffs are set by all after the $n$ periods, otherwise the agreement breaks down and countries permanently revert to Nash tariffs.

To find the lowest cooperative tariff that is weakly renegotiation proof (or simply WRP) we first define each country's payoffs under the alternative situations that can arise. ${ }^{18}$ Let $\tau^{* N}$ represent the vector of Nash tariffs composed of each of the small countries tariffs, $\tau^{* N k}$. In the absence of cooperation, the payoff to the large country equals its government's objective

\footnotetext{
${ }^{17}$ A sufficient condition for the large country to accept $\tau \geq \tau^{G}$ in exchange for small setting $\tau^{* G}$ is for $W\left(\tau^{G}, \boldsymbol{\tau}^{* G}\right) \geq W\left(\tau^{N}, \tau^{* N k}(K)\right)$, which holds strictly when $K=1$. There are sufficient free parameters in the model to ensure that the condition also holds for some $K>1$. But there is some $\bar{K}$ such that $\tau^{* N k}(K)$ is so low that the condition above holds with equality and thus we assume that $K \in(1, \bar{K}]$.

${ }^{18}$ One reason to focus on renegotiation proof agreements is provided by Ludema (2001) who shows that the reliance on reciprocity during dispute settlement at the WTO implies that only trade agreements that are renegotiation proof can be sustained in equilibrium.
} 
evaluated at non-cooperative tariffs:

$$
W^{N} \equiv W\left(\tau^{N}, \boldsymbol{\tau}^{* N}\right)
$$

The cooperative tariff vector (to be found) for the small countries is represented by $\tau^{* C}$ and its representative element, $\tau^{* C k}$, will be common to all $k$ during periods of cooperation since these countries are identical. We denote the large country's cooperative tariff by $\tau^{C}$ so the cooperative payoff of the large country is:

$$
W^{C} \equiv W\left(\tau^{C}, \tau^{* C}\right)
$$

If the large country deviates, it does so by imposing its optimal Nash tariff $\tau^{N}$ on each of the small countries who, in that period, are still setting cooperative tariffs. ${ }^{19}$ The deviation payoff to the large in the period is

$$
W^{D} \equiv W\left(\tau^{N}, \tau^{* C}\right)
$$

According to the strategy we consider if the large country deviates, then in each of the $n$ punishment periods its payoff is

$$
W^{P} \equiv W\left(\tau^{C}, \tau^{* N}\right)
$$

We can then define the large country's continuation payoff after a deviation as:

$$
V^{\tau} \equiv \Sigma_{t=1}^{n} \delta^{t} W^{P}+\Sigma_{t=n+1}^{\infty} \delta^{t} W^{C}
$$

i.e. it undergoes punishment for $n$ periods after which cooperation resumes. Given these payoffs, the incentive compatibility (IC) constraint for the large country to cooperate is

$$
W^{D}+V^{\tau} \leq \frac{W^{C}}{1-\delta}
$$

That is, the sum of the payoff from a deviation, $W^{D}$, and the continuation payoff, $V^{\tau}$, should not exceed the present value of the stream of cooperative payoffs.

Since the per period punishment payoff is lower than the Nash payoff, i.e. $W^{P}<W^{N}$, the punishment phase is subgame perfect only if it is not profitable for the country that is being punished (in this case the large country) to simply abandon the agreement and revert to Nash

\footnotetext{
${ }^{19}$ The large country's deviation level tariff level is independent of the level for the small ones because of the separability across sectors.
} 
tariffs forever. So $V^{\tau}$ must be at least as large as the Nash payoff in order for the cooperative equilibrium to be WRP:

$$
V^{\tau} \geq \frac{\delta}{1-\delta} W^{N}
$$

Because $W^{C}>W^{P}$, the longer the punishment phase $n$, the lower the continuation payoff $V^{\tau}$. Therefore, the maximum punishment phase that is WRP is found by equating the continuation payoff $V^{\tau}$ to the RHS of (14). We define this maximum punishment period as $n^{\max }$, and it is implicitly given by

$$
V^{\tau \min } \equiv \delta \frac{1-\delta^{n^{\max }}}{1-\delta} W^{P}+\frac{\delta^{n^{\max }+1}}{1-\delta} W^{C}=\frac{\delta}{1-\delta} W^{N}
$$

Therefore, the lowest cooperative $W R P$ tariff is obtained at $n^{\max }$ and implicitly defined when (13) holds with equality. Given the maximum WRP punishment it is also simple to see that this cooperative tariff level would obtain under an alternative strategy where if any country deviates then they all permanently revert to Nash. To see this clearly, we substitute $V^{\tau \text { min }}$ in (13) and use the definitions for $W^{D}, W^{N}$ and $W^{C}$ to obtain

$$
W\left(\tau^{N}, \boldsymbol{\tau}^{* C}\right)+\frac{\delta}{1-\delta} W\left(\tau^{N}, \boldsymbol{\tau}^{* N}\right) \leq \frac{W\left(\tau^{C}, \boldsymbol{\tau}^{* C}\right)}{1-\delta}
$$

which is identical to the large country's incentive constraint under infinite Nash reversion. Thus the lowest self-enforcing tariff under infinite Nash reversion or WRP is implicitly defined when (16) holds with equality.

To understand the effect of the coordination externality on cooperation, note that the worst punishment that uncoordinated small countries can inflict on the large one is for each to revert to its individual Nash tariff, $\tau^{* N k}$, which is lower than their coordinated punishment tariff, $\tau^{* N}$. Therefore, for any given cooperative tariff, the total payoff of deviating for the large country, as given by the LHS of (16), is greater relative to the case where small countries coordinate their tariff decisions. In other words, the lack of coordination between small countries increases the large country's incentive to deviate, which is one component of the asymmetric outcome. The other component arises because the coordination externality reduces the incentive of each small country to deviate since the short-term gain from such a deviation is smaller relative to coordination. ${ }^{20}$ To see this more explicitly we now derive the IC for each small country.

\footnotetext{
${ }^{20}$ The incentive to deviate by the small countries is also reduced by the fact that reversion to Nash is more costly to them, which implies that if they would deviate the large country would impose a relatively harsher punishment that would still be WRP.
} 
We use $\tau^{* N k}$ to denote the tariff vector of small countries when a set of them deviate. To clearly highlight the coordination externality one consider two polar cases. First if all small countries deviate at the same time then $\tau^{* N k}=\tau^{* N}$. Second, if only one small country deviates then it charges $\tau^{* N k}$, which must be evaluated at the world price for the large country's export good $x$ when the other $j \neq k$ still set $\tau^{* C j}$. It is simple to show that the results below are qualitatively independent of which of these two alternatives are used. Therefore, in what follows, we consider a scenario where if one small country happens to deviate, then they all do and set their individually optimal Nash tariffs. ${ }^{21}$

Following the derivation for the large country, the IC of a small country is given by

$$
W^{* k}\left(\tau^{C}, \boldsymbol{\tau}^{* N k}\right)+\frac{\delta}{1-\delta} W^{* k}\left(\tau^{N}, \boldsymbol{\tau}^{* N}\right) \leq \frac{W^{* k}\left(\tau^{C}, \boldsymbol{\tau}^{* C}\right)}{1-\delta}
$$

We use these incentive constraints to establish lemma 1, which is a building block to showing that the coordination externality leads to asymmetric tariffs in standard agreements.

Lemma 1 (Asymmetric cooperation incentives under standard agreements): At a given symmetric cooperative tariff the payoff to the large country is higher than the respective aggregate payoff to $K$ uncoordinated small countries under (i) a deviation from cooperation, i.e. $W\left(\tau^{N}, \tau^{* C}\right)>\Sigma_{k} W^{* k}\left(\tau^{C}, \tau^{* N k}\right)$ at $\tau^{C}=\tau^{* C k}$ and (ii) non-cooperation, i.e. $W\left(\tau^{N}, \boldsymbol{\tau}^{* N}\right)>$ $\Sigma_{k} W^{* k}\left(\tau^{N}, \tau^{* N}\right.$.

Proof: To see (i) recall that if all small countries set similar policies then $\Sigma_{k} W^{* k}=K W^{* k}$ and this "regional" welfare measure is mirror symmetric to $W$ so if $\tau^{C}=\tau^{* C k}$ and $\tau^{*}=\tau^{N}$ for all small countries we have the equality below

$$
\begin{aligned}
W(\tau & \left.=\tau^{N}, \boldsymbol{\tau}^{*}=\tau^{C}\right)=K W^{* k}\left(\tau=\tau^{C}, \boldsymbol{\tau}^{*}=\tau^{N}\right) \\
& >K W^{* k}\left(\tau=\tau^{C}, \boldsymbol{\tau}^{* N k}\right)
\end{aligned}
$$

where the inequality arises because $\tau^{N}=\tau^{* N}$ maximizes $K W^{* k}$ for a given $\tau^{C}$ and the elements of $\boldsymbol{\tau}^{* N k}$ are smaller than $\tau^{N}$ (from (6) when $K>1$ ).

\footnotetext{
${ }^{21}$ To understand why the two alternatives yield similar qualitative results note that under either scenario the maximum punishment payoff is identical since it is pinned down by infinite reversion. So, at given cooperative tariffs, the two scenarios differ with respect to the deviation payoff for small countries under individual vs. simultaneous (but uncoordinated) deviation. This payoff differs across the two alternatives because the world price of the good at which $\tau^{* N k}$ is evaluated differs. However, in either case the deviation payoff to the large country is higher than that for the collection of small countries due to their uncoordinated tariff choices, i.e. $\Sigma_{k} W^{* k}\left(\tau^{C}, \boldsymbol{\tau}^{* N k}\right)<W\left(\tau^{N}, \tau^{* C}\right)$, which is key to our results.
} 
To see (ii) note that symmetry implies that

$$
W\left(\tau^{N}, \tau^{*}=\tau^{N}\right)=K W^{* k}\left(\tau^{N}, \tau^{*}=\tau^{N}\right)
$$

which implies that

$$
W\left(\tau^{N}, \boldsymbol{\tau}^{* N}\right)>W\left(\tau^{N}, \boldsymbol{\tau}^{*}=\tau^{N}\right)=K W^{* k}\left(\tau^{N}, \boldsymbol{\tau}^{*}=\tau^{N}\right)
$$

This is because $\tau^{* N}=\tau^{* N k}$ for all $K$ and it is smaller than $\tau^{N}$ (from (6)) and so the export price obtained by the large country is higher relative to when it faces $\tau^{N}$ in all small countries. Furthermore, we have

$$
K W^{* k}\left(\tau^{N}, \boldsymbol{\tau}^{*}=\tau^{N}\right)>K W^{* k}\left(\tau^{N}, \boldsymbol{\tau}^{* N}\right)
$$

This is because $\tau^{*}=\tau^{N}$ for all $K$ maximizes the aggregate payoff of small countries for any given tariff of the large country, not $\tau^{* N}$ whose elements comprise of $K$ tariffs each of which equals $\tau^{* N k}<\tau^{* N}$. Combining the last two inequalities we obtain $W\left(\tau^{N}, \boldsymbol{\tau}^{* N}\right)>$ $\Sigma_{k} W^{* k}\left(\tau^{N}, \boldsymbol{\tau}^{* N}\right)$. QED

Lemma 1 fixes the cooperative tariff at a fixed symmetric level to highlight the fact that the larger country may have a weaker incentive to cooperate than the uncoordinated small countries. We now show that this coordination externality not only generates an imbalance in market power across countries but it also generates asymmetric cooperative tariffs (and thus unequal welfare outcomes) in a trade agreement enforced by the threat of tariff retaliation. As will be clear enforcement is only an issue if the large country is not sufficiently patient to sustain the global optimum tariff in a standard agreement, i.e. if $\delta<\delta_{G}$ where $\delta_{G}$ is implicitly defined to ensure that the the incentive constraint in (16) is satisfied at $\tau^{G}$.

\section{Proposition 1 (Asymmetric outcomes under standard agreements):}

In a standard trade agreement supported by the threat of tariff retaliation, the most cooperative tariff set by a large country exceeds the tariff set by each of the $K$ uncoordinated small countries: i.e. $\tau^{C}>\tau^{* C k}$ whenever the large country is not sufficiently patient to sustain the globally optimal tariff $\left(\delta<\delta_{G}\right)$ and thus this agreement yields higher welfare for the large country than for the set of small ones, i.e. $W\left(\tau^{C}, \boldsymbol{\tau}^{* C}\right)>K W^{* k}\left(\tau^{C}, \boldsymbol{\tau}^{* C}\right)$.

Proof: Suppose that $\delta=\delta_{G}$ so that by definition the incentive constraint of the large country (16) holds with equality when each country sets its tariff to equal the globally optimal tariff $\tau^{G}$. The incentive constraint for a typical small country is similar to (16), except that small 
country exporters face a higher tariff relative to that faced by exporters from the large country, i.e. $\tau^{N}>\tau^{* N k}$, and the payoff of each small country is divided by $K$ (but $K$ cancels out because it enters similarly on both sides of the IC). Thus, the cooperative payoff for the small countries as a group is equal to that for the large one (due to symmetry) and the payoffs for small countries from deviating are smaller, as shown in lemma 1 . This means that at $\delta_{G}$, where (16) holds with equality, there must be slack in the corresponding IC for each small country. If we lower $\delta$ below $\delta_{G}$ then the large country's incentive constraint (16) no longer holds at $\tau^{G}$. So under tariff retaliation, the global optimum is not feasible for $\delta<\delta_{G}$. But the corresponding constraint for each small country continues to hold and has slack, at least for some $\delta<\delta_{G}$.

Since, by definition, for any $\delta<\delta_{G}$ tariff retaliation cannot sustain $\tau^{G}$, to prove Proposition 1 we need only show that when $\delta<\delta_{G}$ the lowest self-enforcing cooperative tariffs used are such that $\tau^{C}>\tau^{* C k}$. We prove this by contradiction. Assume that the lowest self-enforcing cooperative tariffs for all countries is the same, i.e., $\tau^{C}=\tau^{* C k}$ and that it is such that the IC of the large country (16) binds. ${ }^{22}$ We then show that if $\tau^{C}=\tau^{* C k}$ then the IC of a small country (17) has slack implying that such a tariff is not the most cooperative tariff on the part of small countries. Since the RHS of (16) is equal to $K$ times the RHS of (17) at $\tau^{C}=\tau^{* C k}$ (due to symmetry) we need only show that the LHS of (16) exceeds $K$ times the RHS of (17), which is done in lemma 1. Given this there must be some $\tau^{* C k}<\tau^{C}$ for small countries that is still self-enforcing since the reduction in $\tau^{* C k}$ reduces the slack in (17) without violating the large country's IC in (16).

Given the asymmetry in the cooperative tariffs, the large country will have a higher welfare than the collection of small ones even though they are mirror images and there is constant returns to scale in production. ${ }^{23} \mathrm{QED}$

\subsection{Extended Agreements: Efficiency and Equity with Financial Instru- ments}

We now show how the coordination externality can be offset when we extend the set of enforcement instruments to allow for certain type of financial instruments. We show that such an extended trade agreement generates (i) an improvement in global welfare relative to the

\footnotetext{
${ }^{22}$ It is clear that we need not consider the case where $\tau^{C}>\tau^{* C k}$.

${ }^{23}$ This is not to say that the welfare distribution across countries is more unequal under the agreement than non-cooperation since the Nash policies are also asymetric. In fact, if $\delta=\delta_{G}$ the agreement sustains the symmetric global optimum and so generates a more equal welfare distribution than non-cooperation and so this must also be true for at least some $\delta<\delta_{G}$.
} 
standard agreement and (ii) more symmetric welfare outcomes across countries.

First, we consider the exchange of bonds as a means for sustaining cooperation when countries pursue the following strategy. Countries start cooperating by posting a bond with each of its import sources. At the end of a period, if the countries have cooperated then they "return" their respective bonds. If a country deviates from the cooperative tariff, it loses its bond. For cooperation to resume, the deviating country must return the present discounted value of the bond of the injured country. If it does so in the period after the deviation occurs, then tariffs return to the cooperative level. If it does not, cooperation breaks down and all countries switch to their optimal Nash tariffs.

To understand the basic insight, consider a situation where the large country's patience level is just below that which is required to sustain the global optimum under a standard agreement (i.e. $\delta$ is just below $\delta_{G}$ ) while the small countries are patient enough. If we then allowed the large country to post a bond with a value exceeding what it receives from the collection of small countries then its incentive to deviate declines (it stands to lose more from forfeiting its bond) so its cooperative tariff would be lower. While this would also increase each small country's incentive to deviate, it would not affect its cooperative tariff since the incentive constraint of each small country has slack at the initial symmetric tariffs $\tau^{C}=\tau^{* C k}=\tau^{G}$ for some $\delta<\delta_{G}$. We demonstrate this intuition formally below.

Suppose the large country posts a bond of value $b^{k}$ (in units of the numeraire) with each of the small countries it imports from, and receives $\Sigma_{k} b^{* k}$ from them. Since all small countries are ex-ante identical we assume from the start that when cooperating they each post a similar value bond, $b^{* k}=b^{*}$, and receive a similar share of the large country's bond, $b^{k}=b / K$. The $W R P$ incentive constraint for the large country and each of the small countries are respectively given by

$$
\begin{aligned}
W\left(\tau^{N}, \boldsymbol{\tau}^{* C}\right)-b+K b^{*}+V^{b} & \leq \frac{W\left(\tau^{C}, \boldsymbol{\tau}^{* C}\right)}{1-\delta} \\
W^{* k}\left(\tau^{C}, \boldsymbol{\tau}^{* N k}\right)-b^{*}+b / K+V^{* b} & \leq \frac{W^{* k}\left(\tau^{C}, \boldsymbol{\tau}^{* C}\right)}{1-\delta}
\end{aligned}
$$

where their respective continuation payoffs are defined as

$$
\begin{aligned}
V^{b} & \equiv-\frac{\delta K b^{*}}{\delta}+\frac{\delta W\left(\tau^{C}, \boldsymbol{\tau}^{* C}\right)}{1-\delta} \\
V^{* b} & \equiv-\frac{\delta b}{\delta K}+\frac{\delta W^{* k}\left(\tau^{C}, \boldsymbol{\tau}^{* C}\right)}{1-\delta}
\end{aligned}
$$


The first term in the large country's continuation payoff $V^{b}$ equals the present value of the bonds posted by the small countries that must be returned by the large country for cooperation to resume and the second term is the present discounted value of its payoff under cooperation. A similar interpretation applies to a small country's continuation payoff $V^{* b}$.

We now derive the minimum bond values required to enforce the global optimum assuming the WRP constraint is satisfied (which we will verify below). To do so, we substitute these continuation payoffs into (18) and (19) respectively and solve for $b^{g}$ and $b^{* g}$ :

$$
\begin{aligned}
b^{g} & =W\left(\tau^{N}, \boldsymbol{\tau}^{* G}\right)-W\left(\tau^{G}, \boldsymbol{\tau}^{* G}\right) \\
b^{* g} & =W^{* k}\left(\tau^{G}, \boldsymbol{\tau}^{* N}\right)-W^{* k}\left(\tau^{G}, \boldsymbol{\tau}^{* G}\right)
\end{aligned}
$$

These bond values are quite intuitive: the minimum bonds required to achieve globally optimal tariffs are equal to each country's terms-of-trade gain of deviating from those tariffs. Further note that the large country requires a larger bond than the set of $K$ small countries. That is, $b^{g}>K b^{* g}$ since $W\left(\tau^{N}, \boldsymbol{\tau}^{* G}\right)>K W^{* k}\left(\tau^{G}, \boldsymbol{\tau}^{* N \kappa}\right)$ (as proved in Lemma 1) and $W\left(\tau^{G}, \boldsymbol{\tau}^{* G}\right)=$ $K W^{* k}\left(\tau^{G}, \tau^{* G}\right)$ (due to symmetry). In sum, since the large country deviates to an optimal tariff, $\tau^{N}$, that is larger than the optimal tariff of a typical small country $\left(\tau^{* N k}\right)$, its termsof-trade gain from deviating is larger than the corresponding total gain of $K$ uncoordinated small countries. Therefore, the large country must post a larger bond, i.e. $b^{g}>K b^{* g}$, which reduces its incentive to deviate relative to that under tariff retaliation thereby opening up the possibility of increased cooperation.

The final step is to show that there is some $\delta<\delta_{G}$ such that tariff retaliation does not enforce globally optimal tariffs whereas the bonds $b^{g}$ and $b^{* g}$ do while also satisfying the WRP constraint. Let $b^{\max }$ be the bond value that equates the continuation payoff of a small country $V^{* b}$ in $(21)$ to its payoff from abandoning the agreement $W^{* k}\left(\tau^{N}, \tau^{* N}\right) \delta /(1-\delta)$. We have

$$
\begin{aligned}
V^{* b} & =-\frac{b^{\max }}{K}+\frac{\delta W^{* k}\left(\tau^{C}, \boldsymbol{\tau}^{* C}\right)}{1-\delta}=\frac{\delta W^{* k}\left(\tau^{N}, \boldsymbol{\tau}^{* N}\right)}{1-\delta} \\
b^{\max } & =K \frac{\delta\left[W^{* k}\left(\tau^{C}, \boldsymbol{\tau}^{* C}\right)-W^{* k}\left(\tau^{N}, \boldsymbol{\tau}^{* N}\right)\right]}{1-\delta}
\end{aligned}
$$

In other words, if the bond posted by the large country exceeds $b^{\max }$, then a typical small country is better off cheating on the agreement and abandoning it altogether since its continuation payoff falls below what it gets outside the agreement.

Similarly, let $b^{* \max }$ be the value of the bond posted by a small country that equates the 
large country's continuation payoff $V^{b}$ in $(21)$ to $W\left(\tau^{N}, \boldsymbol{\tau}^{* N}\right) \delta /(1-\delta)$, i.e. its payoff from abandoning the agreement. We have

$$
\begin{aligned}
V^{b} & =-K b^{* \max }+\frac{\delta W\left(\tau^{C}, \boldsymbol{\tau}^{* C}\right)}{1-\delta}=\frac{\delta W\left(\tau^{N}, \boldsymbol{\tau}^{* N}\right)}{1-\delta} \\
K b^{* \max } & =\frac{\delta\left[W\left(\tau^{C}, \boldsymbol{\tau}^{* C}\right)-W\left(\tau^{N}, \boldsymbol{\tau}^{* N}\right)\right]}{1-\delta}
\end{aligned}
$$

Note that since $W\left(\tau^{N}, \boldsymbol{\tau}^{* N}\right)>K W^{* k}\left(\tau^{N}, \boldsymbol{\tau}^{* N}\right)$, we have that $b^{\max }>K b^{* \max }$ at any symmetric cooperative tariff. The intuition for this is clear: due to its greater market power, abandoning the agreement is relatively more attractive to the large country and therefore a smaller (aggregate) bond on the part of small countries is necessary to ensure that the large country prefers to resume cooperation by returning bonds of small countries as opposed to abandoning the agreement. In other words, since cooperation is relatively less attractive to the large country, it is willing to suffer a relatively smaller punishment to resume cooperation (as measured by the value of bonds it has to repay to resume cooperation).

As before, if the bonds posted by the small countries exceed $K b^{* \max }$, the continuation payoff of the large country is too low for it to prefer to resume cooperation as opposed to abandoning the agreement altogether. The two WRP constraints together ensure that the bonds required to sustain the global optimum $\left(\tau^{G}, \tau^{* G}\right)$ are not so high that countries prefer to abandon the agreement altogether:

$$
b^{g} \leq b^{\max }\left(\tau^{G}, \boldsymbol{\tau}^{* G}\right) \text { and } b^{* g} \leq b^{* \max }\left(\tau^{G}, \boldsymbol{\tau}^{* G}\right)
$$

First consider $b^{g} \leq b^{\max }\left(\tau^{G}, \boldsymbol{\tau}^{* G}\right)$. Using the definition of $\delta_{G}$ and re-arranging (16) we have

$$
W\left(\tau^{N}, \boldsymbol{\tau}^{* G}\right)-W\left(\tau^{G}, \boldsymbol{\tau}^{* G}\right)=\frac{\delta_{G}\left[W\left(\tau^{G}, \boldsymbol{\tau}^{* G}\right)-W\left(\tau^{N}, \boldsymbol{\tau}^{* N}\right)\right]}{1-\delta_{G}}
$$

Since $b^{g}=W\left(\tau^{N}, \boldsymbol{\tau}^{* G}\right)-W\left(\tau^{G}, \boldsymbol{\tau}^{* G}\right)$ we obtain

$$
b^{g}=\frac{\delta_{G}\left[W\left(\tau^{G}, \boldsymbol{\tau}^{* G}\right)-W\left(\tau^{N}, \boldsymbol{\tau}^{* N}\right)\right]}{1-\delta_{G}}
$$

From the symmetry of $W$ and $K W^{k *}$ at the global optimum we can rewrite $b^{g}$ as

$$
\begin{aligned}
b^{g} & =\frac{\delta_{G}\left[K W^{* k}\left(\tau^{G}, \boldsymbol{\tau}^{* G}\right)-W\left(\tau^{N}, \boldsymbol{\tau}^{* N}\right)\right]}{1-\delta_{G}} \\
& <K \frac{\delta_{G}\left[W^{k *}\left(\tau^{G}, \boldsymbol{\tau}^{* G}\right)-W^{* k}\left(\tau^{N}, \boldsymbol{\tau}^{* N}\right)\right]}{1-\delta_{G}}=b^{\max }\left(\tau^{G}, \boldsymbol{\tau}^{* G}\right)
\end{aligned}
$$


The last inequality follows from the coordination externality, which implies that $W\left(\tau^{N}, \boldsymbol{\tau}^{* N}\right)>$ $W^{*}\left(\tau^{N}, \tau^{* N}\right)$ for $K>1$, as proved in Lemma 1 . Since the RHS in the last line is equal to $b^{\max }$ evaluated at the globally optimal tariffs and it is continuous in $\delta$, we have that when $K>1$ there exist $\delta<\delta_{G}$ s.t. $b^{g} \leq b^{\max }\left(\tau^{G}, \tau^{* G}\right)$. Intuitively, the inequality above says that at the critical discount factor where the large country's incentive constraint just binds under tariff retaliation (i.e. at $\delta=\delta_{G}$ ), the bond $b^{g}$ that the large country has to post in order to sustain cooperation over the global optimum is less than the maximum bond $b^{\max }\left(\tau^{G}, \boldsymbol{\tau}^{* G}\right)$ that satisfies the WRP constraint at globally optimal tariffs (which equals the present discounted value of cooperation to small countries as a whole discounted by one period).

Now consider $b^{* g} \leq b^{* \max }$. Using the value for $b^{* g}$ in (23) on the LHS we have

$$
\begin{aligned}
K b^{* g} & =K\left[W^{* k}\left(\tau^{G}, \boldsymbol{\tau}^{* N k}\right)-W^{* k}\left(\tau^{G}, \boldsymbol{\tau}^{* G}\right)\right]<W\left(\tau^{N}, \boldsymbol{\tau}^{* G}\right)-W\left(\tau^{G}, \boldsymbol{\tau}^{* G}\right) \\
& =\frac{\delta_{G}\left[W\left(\tau^{G}, \boldsymbol{\tau}^{* G}\right)-W\left(\tau^{N}, \boldsymbol{\tau}^{* N}\right)\right]}{1-\delta_{G}}=K b^{* \max }
\end{aligned}
$$

where the first inequality follows from $W\left(\tau^{G}, \boldsymbol{\tau}^{* G}\right)=W^{*}\left(\tau^{G}, \boldsymbol{\tau}^{* G}\right)$ (by symmetry) and $W\left(\tau^{N}, \boldsymbol{\tau}^{* G}\right)>$ $W^{*}\left(\tau^{G}, \boldsymbol{\tau}^{* N k}\right)$ for $K>1$, as proved in Lemma 1 . The equality on the second line follows from the definition of $\delta_{G}$. Since the RHS in the last line is equal to $K b^{* \max }\left(\tau^{G}, \tau^{* G}\right)$ in $(25 \mathrm{~b})$, and is continuous in $\delta_{G}$, we have that when $K>1$ there exists a $\delta<\delta_{G}$ s.t. $b^{* g} \leq b^{* \max }\left(\tau^{G}, \tau^{* G}\right)$. Intuitively, the last inequality says that at the critical discount factor where the large country's incentive constraint just binds under tariff retaliation (i.e. at $\delta=\delta_{G}$ ), the collective value of the bonds posted by small countries required to sustain cooperation over the global optimum is less than the present discounted value of cooperation to the large country (discounted by one period).

\section{Proposition 2 (Improved cooperation and symmetric outcomes with bond ex-} change):

In a trade agreement extended to include bond exchange as an enforcement instrument the large country and the $K$ uncoordinated small countries can sustain the globally optimal tariffs $\left(\tau^{C}=\tau^{* C k}=\tau^{G}\right)$ even if they can not enforce it under a standard agreement. Therefore, for some $\delta<\delta_{G}$, the extended agreement generates (i) an increase in welfare for the small countries; (ii) a global increase in welfare and (iii) a more equitable outcome relative to the standard agreement.

The first part of the proposition follows directly from what we showed above: that there 
exist WRP bonds that sustain the global optimum for at least some $\delta<\delta_{G}$. Since the global optimum tariffs are symmetric it follows that the outcome is more equitable than under the standard agreement where the large country sets higher tariffs than the small ones (part iii). Moreover, the tariffs for the large country are lower under the extended agreement and those for the small countries are no higher (at least for some $\delta<\delta_{G}$ ) so welfare is higher for small countries (part i) and globally since $W+K W^{* k}$ is concave and decreasing in tariffs above the global optimum.

To understand the intuition behind proposition 2 it is useful to consider an extreme case where $K=1$ so the asymmetry disappears. In that case the bonds that can support the global optimum can only be $W R P$ if $\delta=\delta_{G}$, as we can see from (26) and (27) but if the two symmetric countries are that patient then they can sustain $\tau^{G}$ in a standard agreement. More generally, if $\delta<\delta_{G}$ and two symmetric countries exchange bonds then their incentives to deviate remain unchanged because their bonds are of equal value (as shown in Limão and Saggi, 2008). However, if countries are asymmetric then we can require one to post a bigger bond than its smaller partner to offset its incentive to deviate from cooperative tariffs. This increases the incentive to deviate by the smaller country (to keep the bigger bond) but the threat of future tariff retaliation prevents it from doing so.

This proposition provides an enforcement rationale for why some small countries have advocated for trade agreements to be extended to include financial instruments. We now discuss possible obstacles to reforming standard agreements to include financial instruments.

\subsection{Agreement Reform}

There are potentially important obstacles in reforming standard agreements to include financial enforcement instruments. The main obstacle we focus on is the limited ability and/or willingness to post bonds with trading partners. We show that even severe "bond constraints" for small countries can be overcome to achieve the outcomes in Proposition 2 if we design the extended agreement to also include fines. However, if the bond constraint is also severe for the large country then this extended agreement will result in the same asymmetric outcome as the standard one. These results highlight the importance of formally modelling alternative instruments to successfully reform standard agreements. We also discuss how to overcome another potential obstacle; namely, that the large country may oppose moving from the standard to the extended agreement if the latter simply entails lower tariffs for itself but not its smaller 
trading partners.

It is not difficult to motivate or provide a simple formal model of why certain countries may be unable or unwilling to post a large bond at the start of a period in order to induce another country to set a more cooperative tariff. Therefore, instead of committing to a specific motive for this we instead assume that countries face exogenous "bond constraints", i.e. $b<b^{g}$ and $b^{*}<b^{* g}$, and in Proposition 3 we show that the outcome in Proposition 2 can be achieved even if the small countries post no bond at all and the large one posts a bond that is of a value smaller than $b^{g}$ but still positive. So bond constraints may not be an important obstacle to reform a standard agreement even if they are very severe for small countries (if $b^{*}=0$ ). However, in order for agreements to generate efficient and symmetric outcomes in the presence of bond constraints we need to include another financial instrument in the trade agreement, i.e., a fine. The advantage of fines over bonds is that the latter must be posted every period before trading starts whereas fines need only be paid if a deviation ever occurs and are therefore not subject to the same type of financial constraint that bonds are. This raises the question if we need bonds at all in an extended agreement with fines and in Proposition 4 we also constrain $b=0$ to show that they must be included and posted by the large country. ${ }^{24}$

To understand why fines can overcome bond constraints on small but not large countries we must explain why WRP fines face an enforcement issue relative to bonds. Namely, the deviating country has to be induced to pay the fine, whereas the bond is already in the hands of its partner and is thus automatically foregone. Thus fines require some threat of tariff retaliation if they are not paid. We model this tariff threat as a last resort that would only ever materialize if the agreement breaks down. So, the large country will find it easy to enforce large fines, which prevents small ones from deviating even if they post no bond $\left(b^{*}=0\right)$. But small countries will not have the same ability due to the coordination externality and in fact the only fines they can enforce when $b=0$.

Proposition 3 summarizes the results when the extended agreement includes fines and countries face some bond constraints.

\footnotetext{
${ }^{24}$ One simple way to model the "bond constraints" is to assume that production of the numeraire can only take place after policies are set so none of it is available for the initial bonds. If we want the larger country to be able to post some bond we can allow it to have some endowment of the numeraire available at the start of the period. To maintain symmetry we can allow for a similar endowment for the $K$ small countries that is only available after the policies are set so it affects only their ability to post a bond.
} 
Proposition 3 (Improved cooperation and symmetric outcomes with fines and bond constraints):

In a trade agreement extended to include WRP fines and constrained bond exchange ( $b \in$ $\left.\left[\tilde{b}^{g}, b^{g}\right) ; b^{*} \in\left[0, b^{* g}\right)\right)$ the large country and the $K$ uncoordinated small countries can sustain the globally optimal tariffs $\left(\tau^{C}=\tau^{* C k}=\tau^{G}\right)$ even if they can not enforce it under a standard agreement. Therefore, for some $\delta<\delta_{G}$, there is a $\tilde{b}^{g}>0$ such that this agreement generates (i) an increase in welfare for the small countries; (ii) a global increase in welfare and (iii) a more equitable outcome relative to the standard agreement. Furthermore these results hold even if the small countries face severe bond constraints, i.e. if $b^{*}=0$.

\section{Proof:}

To prove Proposition 3 we need only show that for some $\delta<\delta_{G}$ the global optimum can be sustained using bonds $b^{*}=0<b^{* g}$ and $b<b^{g}$. Once that is done the results in (i), (ii) and (iii) follow directly from the same arguments in proposition 2. Consider the following strategy: similarly to before, each country must first post a bond in order for cooperation to begin. We will focus on the case where the total value of this bond is $\tilde{b}>0$ for the large country (equally divided among the $K$ small countries) whereas $b^{*}$ is arbitrarily small, in practice $b^{*}=0$. If a country deviates, it loses its bond but keeps any foreign bond(s) it may hold. But now, if a deviation were to occur then cooperation resumes only after a fine is paid by the deviating country. The incentive constraints for the large and each of the small countries are respectively

$$
\begin{aligned}
W\left(\tau^{N}, \boldsymbol{\tau}^{* G}\right)-\tilde{b}+V^{\tilde{b}} & \leq \frac{W\left(\tau^{G}, \boldsymbol{\tau}^{* G}\right)}{1-\delta} \\
W^{* k}\left(\tau^{G}, \boldsymbol{\tau}^{* N \kappa}\right)+\tilde{b} / K+V^{* \tilde{b}} & \leq \frac{W^{* k}\left(\tau^{G}, \boldsymbol{\tau}^{* G}\right)}{1-\delta}
\end{aligned}
$$

and the minimum continuation payoffs for each are

$$
V^{\tilde{b}} \equiv-\delta f+\frac{\delta W\left(\tau^{G}, \boldsymbol{\tau}^{* G}\right)}{1-\delta} \text { and } V^{* \tilde{b}} \equiv-\delta f^{*}+\frac{\delta W^{* k}\left(\tau^{G}, \boldsymbol{\tau}^{* G}\right)}{1-\delta}
$$

where $f$ and $f^{*}$ are the fine values paid by the large and small countries respectively. As before, we require the continuation payoff to be WRP in that no country prefers to abandon the agreement altogether. This implies that the minimum continuation payoff for each country 
must be no lower than the payoff obtained under non-cooperation:

$$
\begin{aligned}
V^{\tilde{b} \min } & \equiv-\delta f^{\max }+\frac{\delta W\left(\tau^{G}, \boldsymbol{\tau}^{* G}\right)}{1-\delta}=\frac{\delta W\left(\tau^{N}, \boldsymbol{\tau}^{* N}\right)}{1-\delta} \\
V^{* \tilde{b} \min } & \equiv-\delta f^{* \max }+\frac{\delta W^{* k}\left(\tau^{G}, \boldsymbol{\tau}^{* G}\right)}{1-\delta}=\frac{\delta W^{* k}\left(\tau^{N}, \boldsymbol{\tau}^{* N}\right)}{1-\delta}
\end{aligned}
$$

These constraints pin down the maximum fine that each country is willing to pay and rearranging them we can interpret that maximum fine to be the net present discounted value of cooperation:

$$
\begin{aligned}
f^{\max } & =\frac{W\left(\tau^{G}, \boldsymbol{\tau}^{* G}\right)-W\left(\tau^{N}, \boldsymbol{\tau}^{* N}\right)}{1-\delta} \\
f^{* \max } & =\frac{W^{* k}\left(\tau^{G}, \boldsymbol{\tau}^{* G}\right)-W^{* k}\left(\tau^{N}, \boldsymbol{\tau}^{* N}\right)}{1-\delta}
\end{aligned}
$$

Replacing $V^{\tilde{b} \text { min }}$ in $(28)$ by $\delta W\left(\tau^{N}, \tau^{* N}\right) /(1-\delta)$ allows us to solve for the minimum bond required to sustain globally optimal tariffs.

$$
\tilde{b}^{g}=W\left(\tau^{N}, \boldsymbol{\tau}^{* G}\right)+\frac{\delta W\left(\tau^{N}, \boldsymbol{\tau}^{* N}\right)}{1-\delta}-\frac{W\left(\tau^{G}, \boldsymbol{\tau}^{* G}\right)}{1-\delta}
$$

To clearly see the relationship between this and the bond required without fines we rewrite the expression above and use the value of $b^{g}$ in (22) to obtain

$$
\tilde{b}^{g}=\underbrace{\left[W\left(\tau^{N}, \boldsymbol{\tau}^{* G}\right)-W\left(\tau^{G}, \boldsymbol{\tau}^{* G}\right)\right]}_{=b^{g}}-\frac{\delta}{1-\delta}\left[W\left(\tau^{G}, \boldsymbol{\tau}^{* G}\right)-W\left(\tau^{N}, \boldsymbol{\tau}^{* N}\right)\right]<b^{g}
$$

The inequality $\tilde{b}^{g}<b^{g}$ holds because the second term in parenthesis (i.e. $W\left(\tau^{G}, \boldsymbol{\tau}^{* G}\right)-$ $\left.W\left(\tau^{N}, \tau^{* N}\right)\right)$ is positive whenever the number of small countries is small enough that the large country prefers a cooperative trade agreement to a trade war, which is our assumption throughout (see footnote 17). Intuitively, when fines can be used in conjunction with bonds, the large country can post a lower bond because the threat of the maximum fine $f^{\max }$ (off the equilibrium path) ensures that its continuation payoff is no higher than when fines are not used (since it equals $\delta W\left(\tau^{N}, \boldsymbol{\tau}^{* N}\right) /(1-\delta)$ in either case) while the posting of zero bonds by small countries implies that its short term gain of deviating from cooperation is lower relative to the case without fines. It should also be clear that for $\delta<\delta_{G}$ we have $\tilde{b}^{g}>0$ since if $\delta=\delta_{G}$ then $\tilde{b}^{g}=0$ and reducing $\delta$ reduces the gains from cooperation, which is the second term in (32). 
To show that $\tilde{b}^{g}$ does not violate the incentive constraint for small countries in (29) we replace $\tilde{b}^{g}$ and $V^{* b \min }$ into (29) and rearrange it to obtain

$W\left(\tau^{N}, \boldsymbol{\tau}^{* G}\right)+\frac{\delta W\left(\tau^{N}, \boldsymbol{\tau}^{* N}\right)}{1-\delta}+K\left[W^{* k}\left(\tau^{G}, \boldsymbol{\tau}^{* N \kappa}\right)+\frac{\delta W^{* k}\left(\tau^{N}, \boldsymbol{\tau}^{* N}\right)}{1-\delta}\right] \leq \frac{W\left(\tau^{G}, \boldsymbol{\tau}^{* G}\right)}{1-\delta}+K \frac{W^{* k}\left(\tau^{G}, \boldsymbol{\tau}^{* G}\right)}{1-\delta}$

This is simply the sum of the IC in the standard agreement given by (16) and (17) when evaluated at the global optimum. We know that at $\delta_{G}$ the IC for the large country holds with equality at $\tau^{G}$ and the IC for each small country holds with slack (Proposition 1) so (33) holds strictly at $\delta_{G}$ and continuity ensures it must also hold for some $\delta<\delta_{G}$. QED

An immediate corollary is that if the bond constraints were also severe for the large country, i.e. $b=0=b^{*}$, then the proposition would not hold since $\tilde{b}^{g}>0$ unless $\delta=\delta_{G}$. In fact, such constraints generate the same outcome as the standard agreement. The intuition is straightforward: the outcome under the standard agreement is ultimately determined by the threat of the agreement breaking down and thus infinite tariff reversion, which is the same threat that enforces fines so the two yield the same IC. To see this more clearly we can substitute the

minimum continuation payoffs for the extended agreement, $V^{\tilde{b} \text { min }}$ and $V^{* \tilde{b} \min }$, and set $\tilde{b}=0$ in the IC in (28) and (29). Evaluating these at a general cooperative tariff level (instead of requiring it to be the global optimum) we obtain the IC under the standard agreement, (16) and (17). Proposition 4 summarizes this result

Proposition 4: (Equivalence of standard and extended agreements with fines under severe bond constraints):

A trade agreement extended to include WRP fines and subject to severe constraints on bond exchange $\left(b=b^{*}=0\right)$ yields the same outcomes as those in Proposition 1 for a standard trade agreement supported by tariff retaliation.

This last result makes it clear that an extended agreement has to be carefully designed to include the relevant instruments. In this case, what is needed is a bond posted by the large country that removes the need for small countries to coordinate on a particular tariff level in case a retaliation is required.

Any of the agreements considered thus far increases the payoffs for each of the countries relative to non-cooperation. However, large countries and small countries can have different preferred agreements since for some $\delta<\delta_{G}$ we obtain $\tau^{C}>\tau^{* C k}=\tau^{G}$ under the standard agreement (Proposition 1) and $\tau^{C}=\tau^{* C k}=\tau^{G}$ under the extended agreements with $\tilde{b}^{g}$ 
(Propositions 2 and 3). Therefore, the small countries prefer the extended agreement but the large country prefers the standard one since $W\left(\tau, \tau^{* G}\right)$ is increasing in its own tariff when $\tau<\tau^{N}$. This raises the question of whether the large country would want to reform the standard agreement (or choose the extended one if both were on the table). One simple answer is that countries adopt the agreement yielding the highest global political welfare if there is a one-off transfer mechanism available between them. In this case the extended agreement would be adopted since it generates the highest global welfare (Propositions 2 and 3).

The issue is more complicated if there is no initial transfer mechanism to potentially compensate the large country. However, even in this case we argue that a small modification to the extended agreement can make it sufficiently attractive for the large country, namely: to allow it to increase its tariff to a level between the standard and extended agreement, $\tau^{C}>\tau>\tau^{G}$, and require a reduction by the small countries, $\tau^{* C k}<\tau^{G}$. Clearly this would increase the large country welfare relative to the initial extended agreement. Moreover, if the tariff changes are small enough they would not cause a first order loss in global welfare (since it is maximized at $\tau^{G}$ ) so that the extended agreement could still be globally preferred to the standard one. ${ }^{25}$

Naturally, both the initial transfer and the readjustment of cooperative tariffs that make the extended agreement more attractive for the large country also reduce some of its attractiveness to the small ones and would not generate symmetric outcomes. But the small countries would still enjoy higher welfare than under non-cooperation or the standard agreement.

\section{Conclusion}

The multilateral trading system has changed dramatically since 23 founding members signed the GATT in 1947. The WTO now comprises 153 members, many of which are small individually but jointly account for a substantial fraction of trade. The recent emergence of the BRICs and the longer trend of trade liberalization across the developing world has eroded the relative standing of the US and EU in world trade. These salient changes in the global economic landscape have also started to alter the dynamic underlying multilateral trade negotiations. Whereas the first eight rounds of trade negotiations saw limited participation from developing countries and were led primarily by the USA and the EU, the most recent, and currently

\footnotetext{
${ }^{25}$ The logic of propositions 2 and 3 should still apply in this case and in fact we conjecture that the bond required by the large country would be smaller than $\tilde{b}^{g}$ in Proposition 3 since at $\tau>\tau^{G}$ it has less incentive to deviate. When the small countries receive a lower bond they too have less incentive to deviate (but that is at least partially offset by the higher incentive from having $\tau^{* C k}<\tau^{G}$ ).
} 
ongoing, round of negotiations - i.e. the Doha Round - puts (or at least claims to put) the interests of developing countries at center stage.

The increasingly dispersed pattern of world trade along with the increased participation of developing countries at the WTO suggests that the standard two-country paradigm underlying formal models of international trade agreements may no longer adequately capture actual trade negotiations. In this paper we analyze one basic problem that arises under this "new trade order": a coordination externality among countries that import a common good. The externality is strongest when each importer is bilaterally small relative to the exporter, but would have a reasonable degree of market power if it were to coordinate its tariff choices with other importers. This coordination externality implies that smaller countries have less of a threat to use tariffs and therefore a limited ability to bilaterally extract and enforce cooperation from larger countries. Thus international cooperation based on the threat of tariff retaliation yields an asymmetric equilibrium outcome that is biased in favor of the large country.

We examine the use of financial instruments as a means for resolving this coordination externality and the asymmetric outcome that results because of it. To this end, we consider an extended trade agreement under which countries post bonds prior to trading, with the understanding that a country violating the agreement would forfeit its bond. We show that the use of bonds in this fashion does not suffer from the coordination externality that characterizes the tariff choices of small countries. Indeed, we find that when the trade agreement is extended to allow for bonds, the resulting outcome is preferable from both an efficiency and equity perspective. ${ }^{26}$ Since the implementation of such an extended agreement might be problematic due to the inability to post bonds (especially on the part of small countries) we show that our results hold even if small countries do not post any bonds at all provided the extended agreement allows for fines. Furthermore, the use of such fines also allows the large country to post a smaller bond.

The new trade order arising from the relative decline of the US and EU driven by the emergence of several smaller developing countries in the world trading system raises a number of interesting questions and challenges. We argue that to adequately address these new issues,

\footnotetext{
${ }^{26}$ Although we do not consider this in our model, posting bonds with a third party may also help improve cooperation. For example, if bonds of sufficient value are deposited in an escrow fund, tariff retaliation is no longer necessary for sustainting cooperation since the bond posted by the violating country can be used to compensate the injured country. Such an escrow scheme was in fact proposed by Chile in its bilateral trade agreement with the US. "Chile Looks for Monetary Sanctions as Enforcement Mechanism", INSIDE U.S. TRADE 13, $11 / 11 / 2002$.
} 
one needs to go beyond the canonical economic theories of agreements. In this paper, we construct a model that isolates a specific issue that is arguably central to the new global economic landscape: a coordination externality. Future research should consider the implications of such an externality for WTO rules and for the process via which trade concessions are exchanged, e.g. whether to add other instruments to enforce joint punishments and/or adjust the bilateral reciprocity principle. This externality also highlights the incentive of smaller countries to coordinate on a common external tariff via the formation of a customs unions, something that could potentially generate a novel interaction between preferential and multilateral liberalization. ${ }^{27}$ Finally, this new trade order seems to be one where bilateral trade shares and patterns are both dynamic and uncertain, two dimensions that should be better incorporated in future research on trade agreements.

\section{Appendix}

Nash tariff for smaller countries

The tariff in (6) is obtained by solving the following first-order condition for $\tau^{* k}$, where all variables correspond to their import, $x$.

$$
\begin{aligned}
W_{\tau^{* k}}^{k} & =0:\left(1+p_{\tau^{* k}}^{w}\right)\left[\tau^{* k} M_{p}^{* k}+(\lambda-1) S^{* k}\right]-p_{\tau^{* k}}^{w} M^{* k}=0 \\
\tau^{k} & =\frac{p_{\tau^{* k}}^{w}}{1+p_{\tau^{* k}}^{w}} \frac{M^{* k}}{M_{p}^{* k}}-(\lambda-1) \frac{S^{* k}}{M_{p}^{* k}}
\end{aligned}
$$

To obtain $p_{\tau^{* k}}^{w}$ we implicitly differentiate the market clearing condition for $x$ holding all other tariffs constant

$$
\begin{gathered}
M\left(p^{w}\right)+\Sigma_{j \neq k} M^{* j}\left(p^{w}+\tau^{j \neq k}\right)+M^{* k}\left(p^{w}+\tau^{k}\right)=0 \\
p_{\tau^{* k}}^{w}=-\frac{M_{p}^{* k}}{M_{p}+\Sigma_{j \neq k} M_{p}^{* j}+M_{p}^{* k}} \Leftrightarrow \frac{p_{\tau^{* k}}^{w}}{1+p_{\tau^{* k}}^{w}}=\frac{-M_{p}^{* k}}{M_{p}+\Sigma_{j \neq k} M_{p}^{* j}}
\end{gathered}
$$

Replacing in the first order condition and simplifying we obtain

$$
\begin{aligned}
\frac{\tau^{k}}{p^{w}} & =\frac{-M_{p}^{* k}}{M_{p}+\Sigma_{j \neq k} M_{p}^{* j}} \frac{M^{* k}}{p^{w} M_{p}^{* k}}-(\lambda-1) \frac{S^{* k} / M^{* k}}{M_{p}^{* k} p^{w} / M^{* k}} \\
\frac{\tau^{k}}{p^{w}} & =\frac{1}{\varepsilon^{* k}}+(\lambda-1) \frac{S^{* k} / M^{* k}}{\xi^{* k}}
\end{aligned}
$$

\footnotetext{
${ }^{27}$ While some countries have tried to do so (e.g. Mercosur) customs unions are difficult to negotiate and are thus unlikely to eliminate the need for alternatives such as financial instruments in the WTO.
} 
where the last line uses the following definitions of $k^{\prime} s$ import elasticity, $\xi^{* k}$, and inverse foreign net export elasticity, $1 / \varepsilon^{* k}$, respectively

$$
\begin{aligned}
-\xi^{* k} & \equiv-\frac{\partial M^{* k}}{\partial p^{w}} \frac{p^{w}}{M^{* k}}=\frac{-M_{p}^{* k} p^{w}}{M^{* k}} \\
1 / \varepsilon^{* k} & \equiv \frac{M+\Sigma_{j \neq k} M^{* j}}{p^{w}\left(M_{p}+\Sigma_{j \neq k} M_{p}^{* j}\right)}
\end{aligned}
$$

\section{Relationship between elasticities of individual small countries and regional aggregate}

Notice that if all $k$ have the same tariffs then the individual country and regional import demand elasticities are identical

$$
\xi^{* k}=-M_{p}^{* k} p^{w} / M^{* k}=-\left(M_{p}^{*} / K\right) p^{w} /\left(M^{*} / K\right)=\xi^{*}
$$

However, the residual export supply elasticity each individual country faces, $\varepsilon^{* k}$, is different from the one faced by the region as a whole, $\varepsilon^{*}$. Their relationship (derived below) is

$$
\frac{1}{\varepsilon^{* k}}=\frac{1}{K \varepsilon^{*}-\xi^{*}(K-1)}
$$

Moreover, $\frac{1}{\varepsilon^{* k}}<\frac{1}{\varepsilon^{*}}$ for $K>1$. To see this note that $\varepsilon^{* k}=\varepsilon^{*}$ at $K=1$ and $\frac{\partial \varepsilon^{*}}{\partial K}=0$ when these countries set similar tariffs whereas $\frac{\partial}{\partial K} \frac{1}{\varepsilon^{* k}}=\frac{\xi^{*}-\varepsilon^{*}}{\left(\xi^{*}-K \xi^{*}+K \varepsilon^{*}\right)^{2}}<0$ if $K>1$ since $\xi^{*}<\varepsilon^{*}$ for the good imported by this region.

To see (34) note that when small countries are identical they have a similar price so $M_{p}^{* j}=$ $M_{p}^{* k}$ and $\Sigma_{j \neq k} M^{* j}=(K-1) M^{* k}$ so

$$
\begin{aligned}
\varepsilon^{* k} & \equiv \frac{p^{w}\left(M_{p}+\Sigma_{j \neq k} M_{p}^{* j}\right)}{M+\Sigma_{j \neq k} M^{* j}} \\
& =\frac{p^{w}\left(M_{p}+(K-1) M_{p}^{*} / K\right)}{-M^{*}+(K-1) M^{*} / K} \\
& =-\frac{\left(1+(K-1) M_{p}^{*} / K M_{p}\right)}{-1+(K-1) / K} \frac{p^{w} M_{p}}{M} \\
& =\left(1+(K-1) M_{p}^{*} / K M_{p}\right) K \varepsilon^{*} \\
& =K \varepsilon^{*}-(K-1) \xi^{*}
\end{aligned}
$$

where the last line uses $M_{p}^{*} / M_{p}=-\xi^{*} / \varepsilon^{*}$.

Global optimum tariffs (eq. (8)): These are obtained by solving the following first-order condition for $\tau^{C}$

$$
W_{\tau}\left(\tau^{C}\right)+W_{\tau^{*}}\left(\tau^{*}=\tau^{C}\right)=0:\left(1+p_{\tau}^{w}\right)\left[\tau^{C} M_{p}+(\lambda-1) S\right]=0
$$




\section{References}

[1] Bagwell, K. and R. Staiger. 1999. "An Economic Theory of GATT." American Economic Review, 89(1), 215-248.

[2] —. 2005. "Enforcement, Private Political Pressure, and the GATT/WTO Escape Clause." Journal of Legal Studies, 34(2), 471-513.

[3] —. 2011. "What Do Trade Negotiators Negotiate About? Empirical Evidence from the World Trade Organization" American Economic Review, 101(4), 1283-73.

[4] Bagwell, K., Mavroidis, P. and R. Staiger. 2007. "Auctioning Countermeasures in the WTO." Journal of International Economics, 73(2), 309-332.

[5] Besedes, T. and T. Prusa. Forthcoming. "The Role of Extensive and Intensive Margins and Export Growth." Journal of Development Economics.

[6] Broda, C., Limão, N. and D. Weinstein. 2008. "Optimal Tariffs and Market Power: The Evidence," American Economic Review, 98(5), 2032-65.

[7] Bronckers, M. and N. Van Den Broek. 2005. "Financial Compensation in the WTO: Improving the Remedies of WTO Dispute Settlement." Journal of International Economic Law, 8, 101-126.

[8] Grossman, G. and E. Helpman. 1995. "Trade Wars and Trade Talks." Journal of Political Economy, 103, 675-708.

[9] Johnson, H. G. 1953-54. "Optimum Tariffs and Retaliation." Review of Economic Studies, 21, 142-53.

[10] Lawrence, R. 2003. Crimes and Punishments? Retaliation under the WTO. Institute of International Economics, Washington, D.C.

[11] Limão, N. and K. Saggi. 2008. "Tariff Retaliation versus Financial Compensation in the Enforcement of International Trade Agreements," Journal of International Economics 76, 48-60.

[12] Ludema, R. 2001. "Optimal International Trade Agreements and Dispute Settlement Procedures." European Journal of Political Economy, 17, 355-376. 
[13] Ludema, R. \& Anna M. Mayda. 2009. "Do Countries Free Ride on MFN?," Journal of International Economics, 77(2), 137-150.

[14] Mayer, W. 1981. "Theoretical Considerations on Negotiated Tariff Adjustments" Oxford Economic Papers, 33, 135-53.

[15] Park, J-H. 2000. "International trade Agreements Between Countries of Asymmetric Size." Journal of International Economics, 50, 473-495.

[16] Saggi, K. 2009. "Preferential Trade Agreements And Multilateral Tariff Cooperation." International Economic Review, 47(1), 29-57.

[17] Schott, J. 2009. "America, Europe, and the New Trade Order." Business and Politics, $11(3), 1-22$.

[18] Srinivasan, T. N. 1999. "Developing Countries in the World Trading System: From GATT, 1947, to the Third Ministerial Meeting of WTO, 1999", The World Economy, 22 (8), 10471064. 